\title{
Children's Problems During the Preschool Transition: Views of Mexican Teachers
}

\author{
Angel Urbina-Garcia, PhD \\ University of Hull, United Kingdom \\ Chris Kyriacou, Professor of Educational Psychology
}

University of York, United Kingdom

Doi:10.19044/esj.2018.v14n22p154 URL:http://dx.doi.org/10.19044/esj.2018.v14n22p154

\begin{abstract}
Transitioning from preschool to primary school, has been shown to be particularly challenging for children who must adapt to a new environment, set of rules, demands, behaviours and expectations. A number of studies in developed countries have shown that children consistently show problems during this transition, however research is scarce in developing countries. A sample of 30 Mexican teachers from preschool and first grade was recruited to examine common problems children face during this transition to primary school. Results revealed that teachers were somewhat to very concerned about this transition. Preschool teachers reported children showing behaviour problems and having difficulty following directions as the most common problems, while primary school teachers reported the same problems in addition to children showing difficulty taking turns. Teachers' characteristics were associated to a number of children's problems. Overall, Mexican children show similar problems to those reported in the international literature, however further studies are needed in Latin American contexts. Implications for policy and practice are discussed.
\end{abstract}

Keywords: Preschool Transition; Children's Problems; Mexican Teachers; Primary School; Transition in Mexico.

\section{Introduction:}

The transition from preschool to first grade has been recognized as a developmental milestone in children's lives, and has shown to have an important impact on later academic outcomes (Mascareño, 2014; RimmKauffman \& Pianta, 2000; Rosenkoetter, Schroeder, Rous, Hains, Shaw \& McCormick, 2009; Schulting, Malone \& Dodge, 2005; Suzuki, 2013). This period of change has been the focus of research in different countries around the world -but mainly US, Australia and broadly European, which have 
considered a wide range of variables involved in this process. However, research on the preschool to first grade transition is scarce in developing countries and more importantly, there are no empirical studies focusing on the problems children face during this transition in a Latin American educational system such as the case of Mexico, and/or the extent to which findings in developed countries, can be applied to developing countries. As widely supported by previous research and considering the Ecological and Dynamic Model of Transitions (Rimm-Kauffman \& Pianta, 2000), this transition is better understood if we consider, not only the contexts in which children develop, but the experiences of family members and a variety of children's early experiences (Dockett \& Perry, 2007; Rimm-Kauffman \& Pianta, 2000). There is a vast body of research indicating that these early and family experiences, importantly shape children's behaviour during their time at preschool and which will have an important impact as they enter a completely different new setting, the primary school.

Teachers just like parents, have been found to have great influence in children's formal schooling success by supporting their academic achievement and promoting an appropriate personal development (Hamre et al., 2014). Over the years, research has relied on these adults to obtain relevant information about children in different fields of inquiry that would later translate into effective interventions and or policies to support children, their parents and teachers (Richie \& Bentley, 2013; Wildenger \& McIntyre, 2011). In this way, teachers' judgements are relevant to scholars interested in listening to their views with regard to the persons with whom they mainly work; young children. Teachers' views regarding problems children show in classroom, are relevant at theoretical and practical level. On one hand, they provide a glance of the way in which teachers perceive their students in classroom considering a number of variables (e.g., physical environment, school material, social interactions) with which teachers are very familiar. On the other hand, they provide immediate information which stakeholders and policymakers can use in order to create not only immediate interventions to tackle essential problems in classroom, but also relevant empirical evidence to be used to inform educational policies. Teachers are experts not only in their subject matter, but in the variables around their classroom such as educational assessment, curriculum and teaching practices (Perrot, 2014), in addition to being knowledgeable about children's needs and skills with whom they work (Zeichner \& Liston, 2013). By spending a number of hours and coexisting with a number of children, teachers have an amazing amount of information about children's behaviours which could aid the development of educational policies and/or specific transition-related interventions to aid in this process. While teachers are considered a great source of information regarding children school performance (Perrot, 2014), it is also important to bear in mind that 
teachers' judgement may also be influenced by their own previous experiences, pedagogical approach, academic background and system of beliefs (Olsen, 2015). Research has found that teachers' perspectives, are importantly shaped by these variables which in turn, may have a relevant influence in their current teaching behaviour, including expectations and teaching practices (Olsen, 2015). However, Rubie-Davies (2010) found that teachers' behaviours and specifically, teachers' expectations are essential in the teaching-learning process since he found that teachers with higher expectations in pupils, will put greater effort in their educational practices in order to benefit their pupils. The opposite is also true as stated by Rubie-Davis, teachers with low expectations tend to underestimate their students' academic performance. Other scholars have also found that first grade teachers for example, are eager to know more about the expectations of their incoming children in an attempt to shape their practices and thus support students' behaviours and support this period of change (Wildenger \& McIntyre, 2011; Urbina-Garcia, 2014).

Changing from one educational context to another, implies not only changing the physical environment and rules, but also changing roles, duties and identities (Fabian \& Dunlop, 2005; Jindal-Snape, 2010; Vogler et al., 2008). Usual routines carried out in the preschool classroom will not be the same once preschoolers enter first grade of primary school (Lee \& Gogh, 2012; Wildenger, et al 2008). While in preschool, children are used to following a play-based curriculum whereas in the first grade, this will change to a more academic-led curriculum (Li, Mak, Chan, Chu, YMak Lee and Lam, 2013; Urbina-Garcia, 2014). A more "caregiving" approach and a greater interest in child's personal development on behalf of the preschool teacher, will dramatically change to a less inter-personal interest given the number of pupils with whom the first grade teacher will work (Li et al., 2013; Perry, Dockett \& Petriwskyj, 2014). These and additional variables, place children at the core of this process of drastic change which will also challenge children skills' repertoire in order to successfully make this transition. According to Copple and Bredekamp (2009) and Koizumi (2000), changes are very significant in early years for children and therefore, all these changes would imply that starting school, will bring some difficulties for children. In this way, it is of the utmost importance to gather empirical data regarding, not only the set of skills children already master or need, but also the type of problems they may face due to the abovementioned changes. Research shows that children experiencing problems during this transition may lead to a number of negative implications comprising poor academic performance in upper educational levels (Bossaert, et al, 2011) and problems at interpersonal level (McWayne, Green \& Fantuzzo, 2009), such as difficulties in socialization, and emotional regulation (Moreno \& Dongen, 2006). Thus, it is of the utmost important to 
shed light on the problems children show in classroom from the perspective of teachers, to inform effective strategies, school interventions and educational polices to help children during this period of change.

At a glance, in the public Mexican educational system, the ministry of public education (Secretaria de Educacion Publica), runs the preschool and primary school education nationally and sets the criteria for school curricula, assessment and teachers' qualifications. Mexico's educational system is divided in four levels. The first level is preschool which is intended for children under six years old and is optional for parents to send their children, while the second level -primary school- is for children between six-12 years old (third level is secondary school and fourth level is high school). Children who turn six years old by summer are able to start primary school during the fall. Preschool and first grade teachers must hold an undergraduate diploma in preschool education and primary education respectively, to become a classroom teacher. In Mexico, there are private (i.e., which charge tuition fees) and public schools (i.e., free of charge) which are divided in urban, rural, indigenous and communitarian schools. The majority of children aged 5-7 with a low SES, attend to public schools (Cardenas, 2011). Some government institutions -like the one included in this study-, run educational services at preschool level which must follow the criteria established by the ministry of education. Notably, preschool education just became mandatory in 2006 at national level (Urbina-Garcia, 2014) which increases the relevance of this study since it could help identify ways in which the access to first grade of primary school could be eased. However and despite great efforts to make the preschool education mandatory, there are strong critiques regarding the infrastructure and supply of qualified-teachers to provide a good quality of preschool education (Urbina-Garcia, 2014; Moreles, 2011; Rivera \& Guerra, 2005). The institution included in this study, has a national coverage of 29,163 infants, toddlers and pre-schoolers with more than 248 centres in the country and mostly, hosts low SES families. Teachers receive on average $£ 245$ monthly (Santibañez, 2005), which is a little bit above the national minimum average wage, being $£ 2.96$ per day ( $£ 0.37$ pence per hour).

Taken together, these studies highlight the relevance of changing from one educational level to another which undoubtedly, poses important challenges to pre-schoolers and first graders which could jeopardize their stay in primary education. Exploring teachers' perceptions about the problems children face in classroom and teachers' level of concerns about this change, is of the utmost importance since it can provide relevant empirical data to ascertain the difficulties children are facing in a Latin American educational context such as Mexico, which will help design specific strategies or educational interventions to aid this period of change. Information from this study, will also help obtain important empirical data which will help inform 
educational policies to support this transition to primary school considering the particularities of the Mexican context. Thus, the present study addressed three main questions. First, how concerned preschool and first grade teachers are with regard to this period of change? Second, what are the problems teachers perceive preschool and first grade children have during this period? Third, to what extent teachers' characteristics are associated with the problems observed in classroom?

\section{Method \\ Design}

This study followed a quantitative cross-sectional design (Ritchie \& Lewis, 2003) aiming at exploring specific particularities at a certain period of time rather than looking at how participants change over time. To this end, data were collected during the first semester of the beginning of the academic year in both scenarios, preschool and primary school.

\section{Participants}

Thirty teachers in total (15 preschool [PRT] and 15 first grade of primary school [FGT]) from public schools in an urbanized area in Mexico City participated in this study. Socio-demographic data from participants from both groups were gathered and analyzed by means of frequencies and average scores. All preschool participants were female, while first grade teachers included six males and nine females. The average age for PRT was 39.3, while for FGT was 42.4 years old. Interestingly, the number of children reported by teachers in their classroom greatly varied, where FGT teachers had more than twice $(M=31.9)$ the number reported by PRT $(M=13.4)$. FGT reported having more years of experience in teaching $(M=19.2)$ than PRT $(M=13)$. Preschool teachers reported having more working experience $(M=13.4)$ than their colleagues in primary school $(M=5.7)$.

Teachers' educational background ranged from high school to postgraduate. First grade teachers reported a higher educational background in comparison with PRT since eleven FGT had a diploma while interestingly, only six PRT reported to have a diploma which does not meet the minimum requirements as set by the ministry of education. Eleven PRT reported having attended at least one specialised course in the last three years, while only six FGT reported having attended such courses. Only two preschool teachers $(13.3 \%)$ did not share this information.

\section{Measures}

For this study, a survey was developed which included two sections, a) demographic information and b) a rating scale. The first section retrieved information such as age, gender, years of experience, number of children in 
group, etc. The second section focused on the frequency, prevalence and type of problems children face in this transition in both educational levels. The items for the survey were adapted from previous studies regarding problems children show during this period of change (McIntyre et al., 2007; RimmKauffman, 2005; Rimm-Kauffman, et al., 2006). The rating scale included 12 different problems to be rated by teachers on a 5-point Likert type format ranging from " $1=$ Not at all true" to " $5=$ Yes, very true". An example of an item is "Children show difficulty following directions". Teachers' level of concern about this period of change was measured with one-single item where teachers were asked to rate on a 5-point scale, how concerned they were ranging from " $1=$ not at all concerned" to " $5=$ extremely concerned".

\section{Procedure}

The author visited the preschool and primary schools in Mexico City over a two-month period at the beginning of the academic year for datacollection purposes. Fifteen preschool centres belonging to a government institution which provides social services for federal workers and located in the south of the city were selected, while five public primary schools were contacted. Both set of schools are run by the Ministry of Education (SEP). Primary schools selected are located in the northern part of the city and offer free educational service for children aged 6-12. The researcher sought permission from the educational authorities to conduct the present study and once granted, the researcher accessed schools and contacted the headteachers, in order to fully explain the aims of the study and seek permission to contact teachers. Although, ethical approval was not required by the Ministry of Education (SEP, 2012), this study obtained ethical approval form the author's affiliation. Individual consent forms and general information sheets were provided to all the participants prior to any data collection. Headteachers gave specific time to teachers to respond the survey avoiding any negative implication with regards to their daily duties in classroom.

\section{Data Analysis}

Data obtained from the survey completed by teachers, were entered into an electronic file to work with specialised software SPSS (Ver 20). The information was processed to obtain general descriptive statistics of the data. Central tendency and dispersion measures were obtained to explore the prevalence and frequency of children's problems reported by teachers. Potential associations between teachers' socio-demographic data and children's problems were also obtained by computing Pearson Correlation (Coolican, 2014). Given that the data gathered comprised the results from two groups, an analysis of variance was considered to be appropriate for this data and thus a one-way ANOVA was computed (Coolican, 2014; Howitt \& 
Cramer, 2008), looking for the significant variations among preschool and primary school teachers.

\section{Results}

This paper reports results from a larger study focusing on gathering the perceptions of teachers, headteachers and parents during the preschool transition. The present study reports specifically data gathered regarding the problems that children show in both educational levels as reported by teachers.

General concern reported by teachers. Teachers were asked to rate on a 5-point scale, how concerned they were regarding this transition process. A cross-tabulation was obtained showing participants' level of concern in percentages. On average, preschool teachers reported to be somewhat concerned regarding this period of change $(M=3.20)$, however most of the teachers reported to be very $(33.3 \%)$ and extremely $(13.3 \%)$ concerned which accounts for more than $46 \%$. Similarly, primary school teachers, reported being somewhat concerned $(M=3.40)$, however almost half of the participants $(46.7 \%)$ reported being very and extremely concerned $(26.7 \%$ and $20 \%$ respectively).

The prevalence and type of problems perceived by teachers. Three categories were created according to the frequency with which teachers reported the problems experienced by children in the classroom. The categories were evenly distributed to obtain a clear idea of the teachers' position on a continuum scale considering that the maximum points that a teacher could obtain is 60: "Infrequent", "Moderate" and "Frequent". The majority of PRT $(60 \%)$ reported problems with children on a moderate number of occasions, while similarly, the majority of FGT (73\%) reported having a moderate number of problems in classroom.

Similarly, teachers rated on a 5-point Likert scale the problems they perceived in children obtaining the prevalence by calculating means and standard deviations. The two most frequently reported problems by preschool teachers (see Table 1) were "Children show behaviour problems" $(M=2.87$, $S D=1.356)$, and "Children show difficulty following directions" $(M=2.80$, $S D=1.265$ ). More than $60 \%$ of teachers reported children in their classroom having behavioural problems, while more than $50 \%$ of participants' responses ranged from "sometimes true" to "often true" regarding children having difficulty following directions. In contrast, there were two problems less frequently reported: "Children show difficulty working independently" $(M=1.60, S D=1.056)$ with $60 \%$ of participants reporting not at all or rarely true having such problems, and "Children show difficulty adjusting to the schedule or the rhythm of the day" $(M=1.87, S D=1.246)$. For first grade teachers (see Table 2), results indicated three main problems with the highest prevalence: "Children show difficulty following directions" $(M=3.80$, 
$S D=.941)$, "Children show behaviour problems" $(M=3.80, S D=.862)$ and "Children show difficulty taking turns" $(M=3.80$ SD=1.014). Conversely, the lowest problems rated by these teachers were "Children show difficulty respecting my authority as a teacher" $(M=2.60, S D=1.121)$ and "Children show difficulty communicating or language problems" $(M=2.80, S D=9.41)$.

Table 1 Means and Standard Deviations of Children's Problems as Rated by Preschool Teachers

\begin{tabular}{|c|c|c|}
\hline Children's Problems & Mean & Std. Deviation \\
\hline Children show behaviour problems. & 2.87 & 1.356 \\
\hline Difficulty following instructions & 2.80 & 1.265 \\
\hline $\begin{array}{l}\text { 3. Children show difficulty respecting my authority as a } \\
\text { teacher. }\end{array}$ & 2.67 & 1.397 \\
\hline Children show difficulty in carrying out the work. & 2.53 & 1.125 \\
\hline $\begin{array}{l}\text { 5. Children show difficulty taking turns or waiting until } \\
\text { his/her turn to speak. }\end{array}$ & 2.53 & 1.060 \\
\hline $\begin{array}{l}\text { 6. Children show difficulty communicating or language } \\
\text { problems. }\end{array}$ & 2.40 & 1.242 \\
\hline 7. Children show lack of academic skills. & 2.40 & 1.352 \\
\hline $\begin{array}{l}\text { 8. Children show difficulty maintaining attention and } \\
\text { concentration. }\end{array}$ & 2.27 & .799 \\
\hline 9. Children show difficulty working as part of a group. & 2.13 & 1.125 \\
\hline 10. Children show difficulty getting along with other children. & 2.07 & 1.223 \\
\hline $\begin{array}{l}\text { 11. Children show difficulty adjusting to the schedule or the } \\
\text { rhythm of the day. }\end{array}$ & 1.87 & 1.246 \\
\hline 12. Children show difficulty working independently. & 1.60 & 1.056 \\
\hline
\end{tabular}

Table 2 Means and Standard Deviations of Children's Problems as rated by First Grade Teachers

\begin{tabular}{|c|c|c|c|}
\hline & & Mean & Std. Deviation \\
\hline 1. & Children show difficulty following directions. & 3.80 & .941 \\
\hline 2. & Children show behaviour problems. & 3.80 & .862 \\
\hline 3. & $\begin{array}{l}\text { Children show difficulty taking turns or waiting until } \\
\text { his/her turn to speak. }\end{array}$ & 3.80 & 1.014 \\
\hline 4. & $\begin{array}{l}\text { Children show difficulty adjusting to the schedule or the } \\
\text { rhythm of the day. }\end{array}$ & 3.53 & 1.060 \\
\hline 5. & Children show difficulty in carrying out the work. & 3.53 & .915 \\
\hline & Children show difficulty working independently. & 3.47 & 1.125 \\
\hline & $\begin{array}{l}\text { Children show difficulty maintaining attention and } \\
\text { concentration. }\end{array}$ & 3.47 & .990 \\
\hline 8. & Children show lack of academic skills. & 3.47 & .834 \\
\hline & Children show difficulty working as part of a group. & 3.13 & 915 \\
\hline 10. & $\begin{array}{l}\text { Children show difficulty getting along with other } \\
\text { children. }\end{array}$ & 2.87 & .990 \\
\hline 11. & $\begin{array}{l}\text { Children show difficulty communicating or language } \\
\text { problems. }\end{array}$ & 2.80 & 941 \\
\hline & $\begin{array}{l}\text { Children show difficulty respecting my authority as a } \\
\text { teacher. }\end{array}$ & 2.60 & 1.121 \\
\hline
\end{tabular}

In order to analyze the frequency and prevalence of each item, a cross tabulation was computed to obtain percentages from both groups of teachers. These percentages represent teachers' rates on each category of response. For preschool teachers, the results indicated that more than $50 \%$ of teachers 
reported having children with difficulty following directions either as sometimes true $(26.7 \%)$ or often true $(26.7 \%)$. The majority of participants (67\%) reported that their pupils establish appropriate relationships with their peers. More than half of participants $(57.1 \%)$ rated their children as capable of working independently in the preschool classroom while only a few teachers $(21.4 \%)$ found this issue rarely true. Regarding the ability of children to adjust to the daily routine in class, more than half of participants $(53 \%)$ reported not having problems at all in this respect.

More than half of preschool teachers $(60 \%)$ found their children rarely to have problems taking turns, while a third of participants reported this as a common problem (13.3\% sometimes, $13.3 \%$ often true and $6.7 \%$ yes, very true) in their classroom. In relation to children's behavioural problems, the answers varied greatly, but a large number of participants reported sometimes, often and always $(26.6 \%, 20 \%$ and $13.3 \%$ respectively) having children with behaviour problems, which accounts for more $60 \%$ of the sample. Finally, the majority of participants $(73.3 \%)$ reported that children in their class did possess the ability to maintain their attention span adequately during routinely activities.

Results for first grade teachers, revealed that almost all teachers have children with limited academic skills in their classroom as either sometimes true, often true or very true $(53.3 \%, 26.7 \%$ and $13.3 \%$ respectively), accounting for the $93.5 \%$ of the participants. The same percentage of teachers, reported having children with difficulties following directions (sometimes true $33.3 \%$, often true $33.5 \%$ and $26.6 \%$ very true). A large number of participants, accounting for $80 \%$ of the sample, reported having children with difficulties adjusting to the daily routine (sometimes $=26.7 \%$, often $=33.3 \%$ and very true $20 \%$ ), while a similar $80 \%$, reported children not having problems related to communication and/or language use. Almost $67 \%$ of teachers reported having children with difficulties taking turns and children having difficulties remaining seated rated as either, often true and very true. Finally, more than half of participants $(53 \%)$ reported having children with difficulties keeping focused on activities organised by the teacher.

Teachers' characteristics and reported children's problems. Bivariate correlations were calculated using the Pearson product-moment coefficient between teachers' characteristics and children's problems to explore potential relationships between these two variables. On one hand, preschool teachers reporting having attended specific preschool training courses within the last three years was strongly related to teachers reporting children having language problems $(r=.76, p=0.01)$ and children's difficulty adjusting to daily routine $(r=.74, p=0.01)$. Interestingly, the number of courses attended by teachers, positively correlated with four different children's problems, however the highest correlation was found with 
children's difficulty respecting the authority of teachers $(r=.90, p=0.01)$. Finally, number of years of experience as teachers was negatively associated to children showing difficulty following directions $(r=-.61, p=0.05)$ and children carrying out the work assigned $(r=-.57, p=0.05)$. Regarding primary school teachers, results indicated that the maximum academic degree reported by teachers was positively associated with reporting children with difficulty following directions $(r=.61, p=0.05)$, children with difficulties remaining seated throughout the day $(r=.61, p=0.05)$ and children having difficulty understanding the work in the classroom $(r=.70, p=0.05)$. The number of first grade-related training courses attended by teachers was found to be highly correlated to reporting children with difficulty respecting the teacher's authority $(r=.85, p=0.05)$.

Children's Problems: A comparison between groups' means. Interesting differences and similarities in the most and least frequent children's problems reported by teachers were found (see Table 3). However, it is important to mention that given the small sample used in this study, statistical significance could not be established. Nevertheless, this analysis may lead to further research in the future to examine whether there are statistical significant differences or not, in the problems children face during transition.

Table 3 Children's Problems as Reported by Preschool and Primary School Teachers. Children's Problems

\begin{tabular}{|c|c|}
\hline $\begin{array}{l}\text { Most Frequent Problems Reported by } \\
\text { Preschool Teachers }\end{array}$ & $\begin{array}{l}\text { Most Frequent Problems Reported by } \\
\text { Primary School Teachers }\end{array}$ \\
\hline $\begin{array}{l}\text { "Children show behaviour problems" } \\
(M=2.87, S D=1.356),\end{array}$ & $\begin{array}{l}\text { "Children show difficulty following } \\
\text { directions" } \\
(\mathrm{M}=3.80, \mathrm{SD}=.941)\end{array}$ \\
\hline $\begin{array}{l}\text { "Children show difficulty following } \\
\text { directions" } \\
(M=2.80, S D=1.265)\end{array}$ & $\begin{array}{l}\text { "Children show behaviour problems" } \\
(\mathrm{M}=3.80, \mathrm{SD}=.862) \text { and }\end{array}$ \\
\hline & $\begin{array}{l}\text { "Children show difficulty taking turns or } \\
\text { waiting until his/her turn to speak" } \\
(\mathrm{M}=3.80 \mathrm{SD}=1.014) \text {. }\end{array}$ \\
\hline $\begin{array}{l}\text { Least Frequent Problems Reported by } \\
\text { Preschool Teachers }\end{array}$ & $\begin{array}{c}\text { Least Frequent Problems Reported by } \\
\text { Primary School Teachers } \\
\end{array}$ \\
\hline $\begin{array}{l}\text { "Children show difficulty working } \\
\text { independently" } \\
(M=1.60, S D=1.056)\end{array}$ & $\begin{array}{l}\text { "Children show difficulty respecting my } \\
\text { authority as a teacher" } \\
(\mathrm{M}=2.60, \mathrm{SD}=1.121)\end{array}$ \\
\hline $\begin{array}{l}\text { "Children show difficulty adjusting to } \\
\text { the schedule or the rhythm of the day" } \\
(M=1.87, S D=1.246)\end{array}$ & $\begin{array}{l}\text { "Children show difficulty communicating or } \\
\text { language problems" } \\
(\mathrm{M}=2.80, \mathrm{SD}=9.41) \text {. }\end{array}$ \\
\hline
\end{tabular}


It can be seen in Table 3 that preschool and primary school teachers agreed to some extent in the problems they perceive children face during this transition given that both groups reported behavioural problems and following directions as the most frequent problems observed in their classroom. It should be highlighted that the order in which teachers rated these problems as the first and second most frequently reported was different. While PRT placed behavioural problems as the most frequent, FGT rated this problem as the second more frequent. However, primary school teachers reported that children have difficulties taking turns which was not observed in the preschool group.

On the other hand, the least frequent problems reported by teachers are completely different between these groups. While preschool teachers reported children having difficulties working independently and adjusting to the daily routine, primary teachers rated having children with difficulties respecting their authority and showing language problems as least frequent. These results may indicate that difficulties following directions and behavioural problems are mainly observed in both educational scenarios during this transition; however, children may show different strengths in different areas which arguably do not follow a pattern that can be identified by teachers.

Statistical Comparison between Groups. A statistical comparison by using one-way ANOVA revealed interesting statistical differences between groups, however, these results should be interpreted with caution because of the small sample used in the study. Nonetheless, these differences could aid the development of future studies that explore the differences found in greater depth. Results indicate statistically significant differences between the mean scores of the two groups of teachers in the majority of items related to children's problems (see Table 4). These results suggest that first grade teachers report more frequent problems in the classroom regarding a number of different essential skills for this transition, than their counterparts the preschool teachers. Having more problems in first grade may also confirm that children go through a range of challenges during this transition. 
Table 4 One-way ANOVA Results Showing Statistical Significant Differences in Children Problems between Groups based on Means Scores

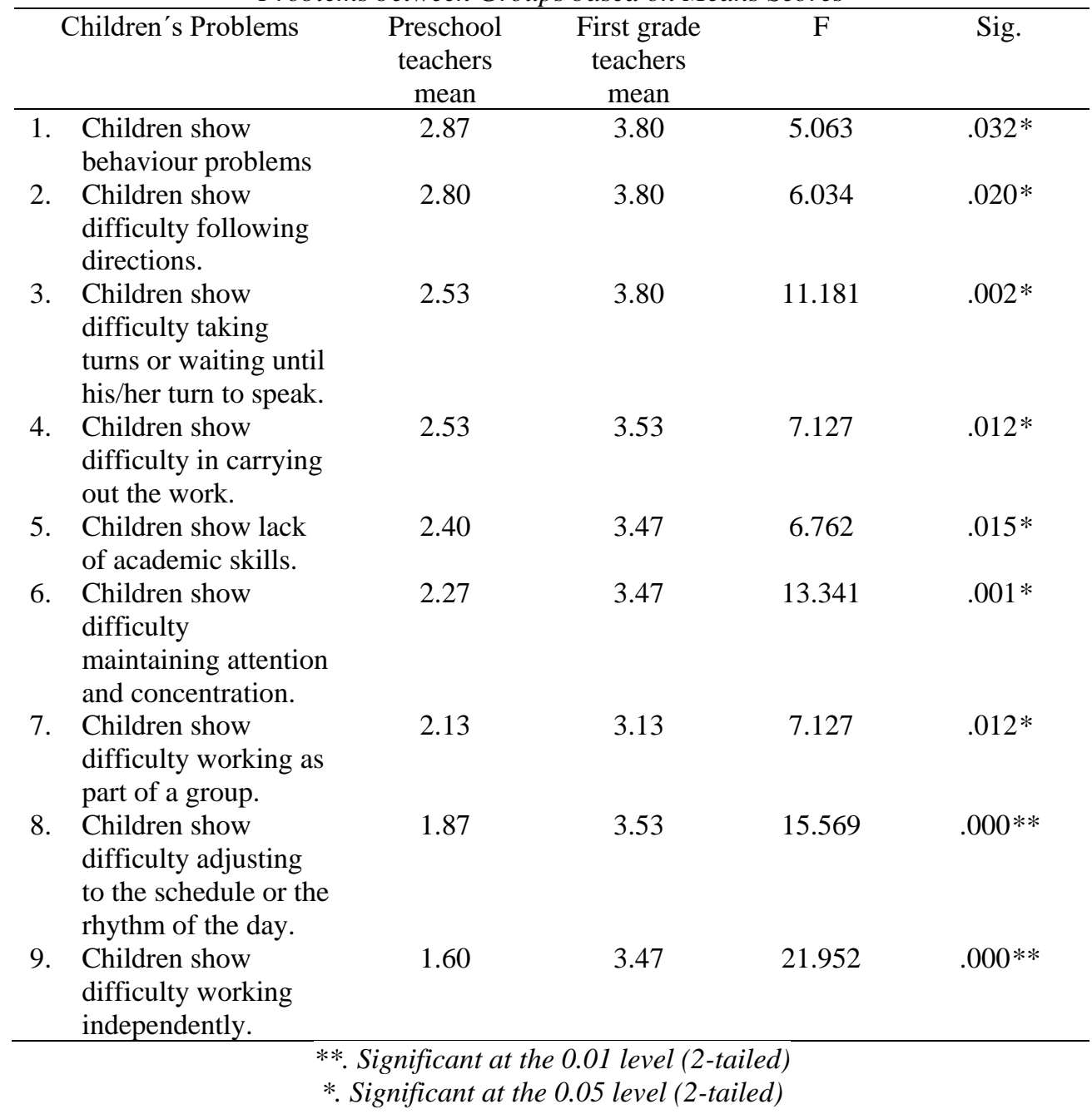

\section{Discussion and Conclusion}

This study sought to explore the problems that children face during the transition from preschool to first grade as reported by preschool and first grade teachers in a Latin American context such as Mexico. In addition, the study explored how concerned teachers' were about this period of change and whether teachers' demographic factors were related to the problems children show in classroom. Generally speaking, results indicate that only half of participants from both groups are concerned about the preschoolers transitioning into first grade which is a view also found in other studies (see Skouteris, Watson \& Lum, 2012). These results are also consistent with those of Della-Vecchia (2012) who found that not only kindergarten but also first grade teachers in the US, reported to be concerned about children's lack of 
academic skills during this period among other aspects. Furthermore, Cassidy (2010) reported that primary-1 teachers were concerned about child adjustment in Scottish schools, while Fisher's (2010) study, found that teachers from preschool and primary school were mainly concerned about the pedagogical approach used in both educational levels. These results seem to indicate that for some teachers this period of change is important and thus they might be aware of its importance as well as the challenges it represents. However, our results also suggest that for other teachers this change may not seem challenging and thus, further research is needed to explore the rationale behind these concerns. Both groups of teachers reported to moderately have children in classroom showing problems, nevertheless, primary school teachers reported to have slightly more problems in classroom than preschool teachers. These findings confirm what Rim-Kauffman, Pianta and Cox (2000) found in a national sample in the US where kindergarten teachers reported a considerable percentage of children in their classroom having similar problems during this shift. Results from the present study, revealed that both groups of teachers reported similar problems in their classroom namely children with behaviour problems and children having difficulty following directions. These findings support previous research from overseas (LoCasale-Crouch et al., 2008; Rim-Kauffman, Pianta \& Cox, 2000) which found that in the teachers' judgement, some children may face major behavioural problems than others and that children at this stage, have difficulties following directions as found by McIntyre et al., (2007). These sets of skills have been found to be intrinsically associated with a successful transition to primary school (Denham, 2010; Hatcher, Nuner \& Paulsel, 2012; Nathanson, Rimm-Kauffman \& Brock, 2009; Stormont et al., 2005) and thus, need further attention. In this study, statistical correlations between teachers' demographics and children's problems were also found. Interestingly, the number of specialised training courses attended by preschool teachers, was positively associated with reporting problems regarding children having difficulties respecting teacher's authority, taking turns, carrying out the classroom activities assigned and keeping focused in classroom activities. Regarding primary school teachers, only the maximum academic degree held by teachers, was significantly associated to children's problems involving difficulties following directions, difficulties remaining seated for longer periods of time and understanding the task assigned by teachers. While these results highlight relevant associations between teachers' characteristics and children's problems -being at the same time consistent with what Schulting and colleagues (2005) found in the US, it is yet to be known the directions of such associations which would enrich our knowledge and understanding about these links. These results confirm previous findings where it has been suggested that teachers attending to specialised training, is associated with 
implementing more transition practices (Rous et al., 2010) which are at the same time, associated with fewer children's problems (Perry, Dockett \& Petriwskyj, 2014). This study also found statistical significant differences when comparing both groups of teachers, however care must be taken when interpreting these results given the small sample used. Findings from this study revealed that first grade teachers reported more frequent problems in the classroom than preschool teachers. These results are consistent with a number of previous studies where teachers have reported children facing different challenges during the change between one school and another (RimKauffman, Pianta \& Cox, 2000; Robinson \& Diamond, 2013; Wildenger \& McIntyre, 2012). A possible explanation for this finding, might be related to individual differences among children as suggested by the literature from a developmental perspective (Copple \& Bredekemp, 2009), where pupils may have a well-developed set of skills while some other skills have not been mastered. Moreover, as some scholars suggest, the different backgrounds of children (e.g., early home experiences) must be considered given the opportunities offered at home to develop skills related not only to the personal domain, but also to the academic one (Fraley, Roisman \& Haltigan, 2013; Jonassen \& Grabowski, 2012; McIntyre et al., 2010; Urbina-Garcia, 2006). Another possible explanation may rely on the so-called discontinuity in the curriculum (Chun, 2013; Di Santo \& Bernan, 2012; Sink, Edwards \& Weir, 2007), whereby the preschool syllabus emphasises a play-based approach where children are constantly playing around the classroom in the different areas designated, while the first grade curriculum emphasises a more academic-led environment which requires children to be seated in their chairs paying attention to the teacher and carrying out academic work.

Although this study provides relevant information about teachers' concerns and the problems children face during this transition in public schools, there are few limitations important to consider. Firstly, given that the scale used in this study was created based upon international literature -and more specifically from scales developed in countries such as United Kingdom, Australia, New Zealand and US, it could be speculated that the inclusion of specific children's problems to be rated by teachers, may have not reflected the type and range of problems encountered by Latin-American teachers in their classrooms. Secondly, although this study yielded important empirical information from a Latin-American context with regard to this transition process, the small sample used in this study does not allow for generalizations, calling for the need to propose additional studies with a larger sample. Thirdly, statistically significant findings were noted in the study; however, these significant findings must be interpreted with caution due to the sample size used. Large-scale studies will allow to carry out additional statistical tests and reach more conclusive arguments. Taken together, these findings contribute to 
the existing international literature by shedding light on Latin American teachers' perspectives whereby, it is reported that preschool and first grade children do indeed, face a number of important problems during this transition. In addition these results advances our knowledge and understanding regarding the way in which teachers' characteristics in this part of the world, are associated with the problems children show in classrooms. The evidence obtained, seems to suggest that a Latin American educational context such as Mexico, might be not that different from those contexts where most of the preschool transition research has been carried out such as Australia, US, England, Iceland, Italy and so forth. It is clear from these results, that half of the participants from each group, are either very or extremely concerned about this period pf change for children. However, further research is needed in order to explore additional problems teachers may have in their classroom which were not included in this study, in addition to exploring the rationale behind the concerns expressed in this sample and the lack of concern on behalf of other participants. More research is needed to examine the type of problems children display in other Latin American countries which will allow to obtain relevant empirical data to inform educational policies in this region of the world.

\section{Acknowledgements}

The budget for this study was administered by CONACYT- Mexico (National Council of Science and Technology). I would like to thank to all the participants for their valuable time invested in this study and to all Mexican citizens whose taxes, made possible this study.

\section{References:}

1. Bossaert, G., Doumen, S., Buyse, E., \& Verschueren, K. (2011). Predicting children's academic achievement after the transition to first grade: A two-year longitudinal study. Journal of Applied Developmental Psychology, 32(2), 47-57. http://doi.org/10.1016/j.appdev.2010.12.002

2. Cárdenas Denham, S. (2011). Escuelas de doble turno en México: una estimación de diferencias asociadas con su implementación. Revista mexicana de investigación educativa, 16(50), 801-827.

3. Cassidy, M. (2010). "They Do It Anyway": A study of primary 1 teachers' perceptions of children's transition into primary education. Early Years: An International Journal of Research and Development, 25(2), 143-153.

4. Chun, W. N. (2013). A study of children's difficulties in transition to school in Hong Kong. Early Child Development and Care, 173(1), 8396. 
5. Copple, C., \& Bredekamp, S. (2009). Developmentally appropriate practice in early childhood programs. Washington, DC: National Association for the Education of Young Children.

6. Coolican, H. (2014). Research methods and statistics in psychology. Psychology Press.

7. Della Vecchia, L. (2012). Preschool through first grade transition interventions: Teachers' perceptions of the impact on students. (Doctoral dissertation). Retrieved from ProQuest. Dissertation Abstracts International Section A, 73, 1644.

8. Denham, S.A. (2010). Early Education \& Development SocialEmotional Competence as Support for School Readiness: What Is It and How Do We Assess It?, (June, 2012),37-41

9. Di Santo, A., \& Berman, R. (2012). Beyond the preschool years: Children's perceptions about starting kindergarten. Children \& Society, 26(6), 469-479

10. Fabian, H. \& Dunlop, W. (2005). 'The Importance of Play in the Transition to School' in J. R. Moyles (Ed) The Excellence of Play 2nd edition. Berkshire: Open University Press/McGraw-Hill.

11. Fisher, J. (2010). Moving on to Key Stage 1: Improving Transition from the Early Years Foundation Stage. London: McGraw Hill International

12. Fraley, R. C., Roisman, G. I., \& Haltigan, J. D. (2013). The legacy of early experiences in development: Formalizing alternative models of how early experiences are carried forward over time. Developmental Psychology, 49(1), 109.

13. Hamre, B., Hatfield, B.m Pianta, R. \& Jamil, F. (2014). Evidence for general and domain specific elements of teacher-child interactions: Associations with preschool children's development. Child Development, 85(3), 1257-1274

14. Hatcher, B., Nuner, J., \& Paulsel, J. (2012). Kindergarten Readiness and Preschools: Teachers' and Parents' Beliefs within and across Programs. Early Childhood Research \& Practice, 14(2), n2.

15. Howitt, D. \& Cramer, D. (2008). Introduction to Statistics in Psychology. England: Pearson Education Limited.

16. Jindal-Snape, D. (Ed) (2010). Educational Transitions: Moving Stories from around the world. New York \& London: Routledge

17. Jonassen, D. H., \& Grabowski, B. L. (2012). Handbook of individual differences learning and instruction. New Jersey: Routledge.

18. Koizumi, R. (2000). Anchor points in transitions to a new school environment. The Journal of Primary Prevention, 20(3), 175-187.

19. Lee, S. \& Gogh, G. (2012). Action Research to Address the Transition to Kindergarten to Primary School: Children's Authentic Learning, 
Construction Play and Pretend Play. Early Childhood Research and Practice, 14(1).

20. Li, H. C. W., Mak, Y. W., Chan, S. S., Chu, A. K., Lee, E. Y., \& Lam, T. H. (2013). Effectiveness of a play-integrated primary one preparatory programme to enhance a smooth transition for children. Journal of health psychology. 18(1) 10- 25. Doi: 1359105311434052.

21. LoCasale-Crouch, J., Mashburn, A. J., Downer, J. T., \& Pianta, R. C. (2008). Pre-kindergarten teachers' use of transition practices and children's adjustment to kindergarten. Early Childhood Research Quarterly, 23(1), 124-139

22. McIntyre, L. L., Eckert, T.L., Fiese, B. H.m DiGennaro, F. D., \& Wildenger, L. K. (2007). Transition to Kindergarten: Family Experiences and Involvement. Early Childhood Education Journal, 35(1), 83-88. http://doi.org/10.10007/s10643-007-0175-6

23. McIntyre, L. L., Eckert, T. L., Fiese, B. H.m DiGennaro, F. D., \& Wildenger, L. K. (2010). Family Concerns Surrounding Kindergarten Transition: A Comparison of Students in Special and General Education. Early Childhood Education Journal, 38(4), 259-263. ttp://doi.org/10.1007/s10643-010-0416-y

24. McWayne, C. M., Green, L., \& Fantuzzo, J. (2009). A variable-and Person-Oriented Investigation of Preschool Competencies and Head Start Children's Transition to Kindergarten and First Grade. Applied Developmental Science, 13(1), 1-15

25. Moreles, V. J. (2011). El Uso de la Investigacion en la Reforma de la Educacion Prescolar en Mexico. Un caso de evidencia basada en la politica. Revista Mexicana de Investigacion Educativa, 16 (50), 725750 .

26. Moreno, T. \& Dongen, J. (2006) Transitions in the early years: A learning opportunity. The Netherlands: Bernard van Leer Foundation.

27. Nathanson, L., Rimm-Kaufman, S.E., \& Brock, L.L. (2009). Kindergarten adjustment difficulty: The Contribution of children's effortful control and parental control. Early Education and Development, 20(5), 775-798.

28. Olsen, B. (2015). Teaching what they learn, learning what they live: How teachers' personal histories shape their professional development. Routledge.

29. Perrott, E. (2014). Effective teaching: A practical guide to improving your teaching. Routledge. Perry, B., Dockett, S., \& Petriwskyj, A. (2014). Transitions to School-International Research, Policy and Practice. Dordrecht: Springer Netherlands.

30. Rimm-Kaufman, S.E. (2005). Survey of Early School Adjustment. Unpublished measure, University of Virginia, Charlottesville, VA. 
31. Rimm-Kaufman, S. E., Pianta, R. C., Cox, M. J., Carolina, N., \& Hill, C. (2006). Teachers' Judgments of Problems in the Transition to Kindergarten. Human Development, 166(2), 147-166.

32. Ritchie, J., \& Lewis, J. (2003). Qualitative research in practice: A guide for social science students and researchers. London: Sage.

33. Rivera, F. L. \& Guerra, M. M. (2005). Retos de la educación preescolar obligatoria en México: la transformación del modelo de supervisión escolar. REICE-Revista Electrónica Iberoamericana sobre Calidad, Eficacia y Cambio en Educación, 3(1).

34. Robinson, C. D., \& Diamond, K. E. (2013). A Quantitative Study of Head Start Children's Strengths, Families' Perspectives, and Teachers' Ratings in the Transition to Kindergarten. Early Childhood Education Journal, 42(2), 77-84. http://doi.org/10.1007/s10643-013-0587-4

35. Rous, B., Hallam, R., McCormick, K., \& Cox, M. (2010). Practices that support the transition to public preschool programs: Results from a National Survey. Early Childhood Research Quarterly, 25(1), 17-32. doi:10.1016/j.ecresq.2009.09.001

36. Rubie-Davies, C. M. (2010). Teacher expectations and perceptions of student attributes: Is there a relationship? The British Journal of Educational Psychology, 80(Pt 1), 121-35. http://doi.org/10.1348/000709909X466334

37. Santibañez, L., Vernez, G., \& Razquin, P. (2005). Education in Mexico: Challenges and opportunities. Santa Monica, CA: RAND Corporation

38. Schulting, A. B., Malone, P. S., \& Dodge, K. A. (2005). The effect of school-based kindergarten transition policies and practices on child academic outcomes. Developmental Psychology, 41(6), 860-871.

39. Secretaria de Educación Pública (SEP) (2012) Sistema Nacional De Información Educativa. México. Retrieved from http://www.snie.sep.gob.mx/indicadores_y_pronosticos.html

40. Sink, C. A., Edwards, C. N., \& Weir, S. J. (2007). Helping Children Transition from Kindergarten to First Grade. Psychology.

41. Skouteris, H., Watson, B., \& Lum, J. (2012). Preschool children's transition to formal schooling: The importance of collaboration between teachers, parents and children. Australasian Journal of Early Childhood, 37(4), 78.

42. Stormont, M., Beckner, R., Mitchell, B., \& Richter, M. (2005). Supporting Successful Transition to Kindergarten: General Challenges and Specific Implications for Students with Problem Behavior. Psychology in the Schools, 42(8), 765-778. http://doi.org/10.1002/pits.20111

43. Suzuki, M. (2013) Japanese Children's Transition between Two 
Worlds: Mapping How Kindergarten and Elementary-School Teachers Think about Chilren and Their Activities. (Doctoral Dissertation). Retrieved from ProQuest (Accessed on December, 2013).

44. UNESCO (2015) Position Paper on Education Post-2015; Paris. UNESCO

45. Urbina-Garcia, M. A. (2006) Programa de Transición del Preescolar a la Primaria [Preschool to First Grade Transition Intervention Programme ]. (Master's Dissertation). Available from TesiUNAM and Online Thesis Data Base Universidad Nacional Autónoma de México, UNAM; México.

46. Urbina-Garcia, M. A. (2014). Transition from Preschool to First Grade Primary School in Mexico: The Perceptions of Teachers, Headteachers and Parents (Doctoral dissertation, University of York).

47. Vogler, P., Crivello, G. and Woodhead, M. (2008) Early childhood transitions research: A review of concepts, theory, and practice. Working Paper No. 48. The Hague, The Netherlands: Bernard van Leer Foundation: The Hague, The Netherlands

48. Wildenger, L. \& McIntyre, L. (2011). Family concerns and involvement during kindergarten transition. Journal of Child and families studies. 20 387-396. Retrieved October 25, 2011, from http://www.springerlink.com/content/j507382025477178/

49. Wildenger, L. K., \& McIntyre, L. L. (2012). Investigating the Relation Between Kindergarten Preparation and Child Socio-Behavioral School Outcomes. Early Childhood Education Journal, 40(3), 169-176. http://doi.org/10.1007/s10643-012-0509-X

50. Zeichner, K. M., \& Liston, D. P. (2013). Reflective teaching: An introduction. Routledge. 